\title{
Representing and Reasoning about Motion in a Two-Dimensional World
}

\author{
Wanlin Pang* André Trudel \\ Jodrey School of Computer Science \\ Acadia University \\ Wolfville, Nova Scotia, Canada, B0P 1X0 \\ Email: pang@cs.uregina.ca andre.trudel@AcadiaU.ca
}

\begin{abstract}
This paper presents a point based spatio-temporal first order logic for representing the qualitative and quantitative spatial temporal knowledge needed to reason about motion in a two-dimensional space. The knowledge of a simplified world, a two-dimensional street network with active traffic lights, is represented, and the reasoning problem of how a robot moves from one place to another in the world is formalized with the proposed logic.
\end{abstract}

\section{Introduction}

Some of the most common human activities are walking, route-finding and navigation, which involve dealing with the physical world - the three dimensional space we live in. For example, when getting up in the morning, one goes from the bedroom to the bathroom through the door; finds something in the right place in the kitchen to eat and drink; walks (or drives) along some existing routes to school; finds one's way to the classroom through the building.

One does all of these daily things without any conscious thought or calculation when in a familiar environment. What kind of

\footnotetext{
* Current address: Dept. of Computer Science, University of Regina, Regina, Saskatchewan, Canada S4S 0A2
}

knowledge does one have about the environment in which one lives? How does one use this knowledge in daily activities of walking, route-finding or navigation? Is it this kind of knowledge that assures us that we can reach our destination? Further, is this knowledge representable, learnable, and manipulatable? Can this kind of knowledge be stored in a robot to enable it to do the same thing? Exploring these questions leads us closer to an explicit understanding of the commonsense knowledge of space, which we consider important for understanding how people deal with space and also important for building robots capable of dealing with their environments.

This paper presents a point based spatiotemporal logic to represent the qualitative and quantitative spatial temporal knowledge needed to reason about motion in a twodimensional space. In the next section we present the logic with detailed syntax and semantics. Then we examine the problem of how to get from one place to another in a twodimensional street-network and formalize this problem in the proposed logic.

\section{A spatio-temporal logic}

The proposed spatio-temporal logic is based on a first order temporal logic called RGCH [2]. RGCH uses real valued functions to represent point based temporal information and these functions are integrated to represent interval based information. We extend RGCH's real valued functions to include a spatial pa- 
rameter so that it can be used to represent knowledge of both space and time.

\subsection{Syntax}

Given the following disjoint sets:

- TC: a set of temporal constant symbols;

- $T V$ : a set of temporal variable symbols;

- $O C$ : a set of orientational constant symbols;

- $O V$ : a set of orientational variable symbols;

- $L C$ : a set of locational constant symbols;

- $L V$ : a set of locational variable symbols;

- $U C$ : a set of non-spatio-temporal constant symbols;

- $U V:$ a set of non-spatio-temporal variable symbols;

- UF: a set of non-spatio-temporal function symbols;

- $F$ : a set of function symbols.

Terms are defined as follows:

- All members of $T C$ and $T V$ are temporal terms;

- If $t_{1}$ and $t_{2}$ are temporal terms, then $t_{1}+$ $t_{2}, t_{1}-t_{2}$ and $t_{1} \times t_{2}$ are temporal terms;

- All members of $O C$ and $O V$ are orientational terms;

- If $d_{1}$ and $d_{2}$ are orientational terms, then $\operatorname{add}\left(d_{1}, d_{2}\right), \operatorname{sub}\left(d_{1}, d_{2}\right)$ and opposite $\left(d_{1}\right)$ are orientational terms;

- All members of $L C$ and $L V$ are locational terms;

- If $p_{1}$ and $p_{2}$ are locational terms, then $\left|p_{1}, p_{2}\right|$ is a locational term, and $\operatorname{orient}\left(p_{1}, p_{2}\right)$ is an orientational term;

- All orientational and locational terms are spatial terms;
- All members of $U C$ and $U V$ are nonspatio-temporal terms;

- If term $_{1}$, term $_{2}, \ldots$, term $_{n}$ are nonspatio-temporal terms, and $f \in U F$ is an n_ary function, then

fterm $_{1}$, term $_{2}, \ldots$, term $\left._{n}\right)$, is a nonspatio-temporal term;

- All temporal, spatial and non-spatiotemporal terms are terms;

- If term $_{1}$, term $_{2}, \ldots$,term $n$ are nonspatio-temporal terms, $t, t_{1}, t_{2}$ are temporal terms, $s, s_{1}, s_{2}$ are spatial terms, and $f \in F$ is an $(n+2)$ _ary function, then $f\left(\right.$ term $_{1}$, term $_{2}, \ldots$, term $\left._{n}, s, t\right)$, $\int_{t_{1}}^{t_{2}} f\left(\right.$ term $_{1}$, term $_{2}, \ldots$, term $\left._{n}, s, t\right) d t$, $\int_{s_{1}}^{s_{2}} f\left(\right.$ term $_{1}$, term $_{2}, \ldots$, term $\left._{n}, s, t\right) d s$ are terms.

The well-formed formulas (wffs) are defined as follows:

- If term term $_{2}$ are terms, then term $_{1}=$ term $_{2}$ is a wff;

- If $t_{1}, t_{2}$ are temporal terms, then $t_{1}<t_{2}$ is a wff;

- If $d_{1}, d_{2}$ are orientational terms, then $d_{1}<d_{2}$ is a wff;

- If $\varphi_{1}, \varphi_{2}$ are wffs, then $\neg \varphi_{1}, \varphi_{1} \wedge \varphi_{2}$ are wffs;

- If $\varphi$ is a wff and $v$ is a variable from $T V$, $O V, L V$ or $U V$, then $\forall v(\varphi)$ is a wff.

We assume the usual definitions of $\vee, \Rightarrow, \exists$, $\exists$ !, $\oplus, \leq,>, \geq$, etc.

\subsection{Semantics}

The real number set $\mathbb{R}$ is the semantic domain for temporal objects, $\mathbb{R} \times \mathbb{R}$ for locational objects, a subset $\mathbb{R}^{\prime}$ of $\mathbb{R}(-180,180]$ for orientational objects and $\mathbb{U}$, a non-empty set of individuals, is the semantic domain for the remaining objects.

An interpretation is a tuple $I=\langle\mathbb{R}, \mathbb{U}, \alpha\rangle$ where $\alpha$ is an interpretation function that 
maps each $(n+2)$ _ary function in $F$ to an $(\mathrm{n}+3)$ _ary function from $\mathbb{U}^{n} \times \mathbb{R}^{2} \times \mathbb{R}$ to $\mathbb{R}$ if it contains a locational argument, or to an $(\mathrm{n}+2)$ _ary function from $\mathbb{U}^{n} \times \mathbb{R}^{\prime} \times \mathbb{R}$ to $\mathbb{R}$ if it contains an orientational argument, and maps each n_ary function in $U F$ to an n_ary function from $\mathbb{U}^{n}$ to $\mathbb{U}$.

A variable assignment $\beta$ is a function that maps each temporal variable to an element of $\mathbb{R}$, each locational variable to an element of $\mathbb{R}^{2}$, each orientational variable to an element of $I R^{\prime}$ and each other variable to an element of $\mathbb{U}$.

The meaning of terms is defined as follows:

- For a constant $c \in T C(L C, O C$ or $U C)$, $I(c)=\alpha(c)$

- For a variable $v \in T V(L V, O V$ or $U V)$, $I(v)=\beta(v)$;

- For an n_ary function $f \in F$ (or $U F$ ) and terms term $_{1}$, term $_{2}, \ldots$, term $_{n}$,

$I\left(f\left(\right.\right.$ term $m_{1}$, term $_{2}, \ldots$, term $\left.\left.m_{n}\right)\right)=$ $\alpha(f)\left(I\left(\right.\right.$ term $\left._{1}\right), I\left(\right.$ term $\left._{2}\right), \ldots, I\left(\right.$ term $\left.\left.m_{n}\right)\right) ;$

- For an $(n+2)$ _ary function $f \in F$ and terms term $_{1}, \ldots$, term $_{n}, s, s_{1}, s_{2}, t, t_{1}, t_{2}$, $I\left(\int_{t_{1}}^{t_{2}} f\left(\right.\right.$ term $_{1}, \ldots$, term $\left.\left._{n}, s, t\right) d t\right)=$ $\int_{I\left(t_{1}\right)}^{I\left(t_{2}\right)} \alpha(f)\left(I\left(\right.\right.$ term $\left._{1}\right), \ldots, I\left(\right.$ term $\left.\left._{n}\right), I(s), t\right) d t$, $I\left(\int_{s_{1}}^{s_{2}} f\left(\right.\right.$ term $_{1}, \ldots$, term $\left.\left._{n}, s, t\right) d s\right)=$ $\int_{I\left(s_{1}\right)}^{I\left(s_{2}\right)} \alpha(f)\left(I\left(\right.\right.$ term $\left._{1}\right), \ldots, I\left(\right.$ term $\left.\left._{n}\right), s, I(t)\right) d s ;$

- If $t_{1}, t_{2}$ are temporal terms, then

$I\left(t_{1}+t_{2}\right)=I\left(t_{1}\right)+I\left(t_{2}\right)$,

$I\left(t_{1}-t_{2}\right)=I\left(t_{1}\right)-I\left(t_{2}\right)$,

$I\left(t_{1} \times t_{2}\right)=I\left(t_{1}\right) \times I\left(t_{2}\right) ;$

- If $d_{1}, d_{2}$ are orientational terms, then $I\left(\operatorname{add}\left(d_{1}, d_{2}\right)\right)=$

$\int I\left(d_{1}\right)+I\left(d_{2}\right)$ if $-180<I\left(d_{1}\right)+I\left(d_{2}\right) \leq 180$,

$\left\{I\left(d_{1}\right)+I\left(d_{2}\right)+360\right.$ if $I\left(d_{1}\right)+I\left(d_{2}\right)<-180$, $\left\{I\left(d_{1}\right)+I\left(d_{2}\right)-360\right.$ if $180 \leq I\left(d_{1}\right)+I\left(d_{2}\right)$,

$I\left(\operatorname{sub}\left(d_{1}, d_{2}\right)\right)=$

$\int I\left(d_{1}\right)-I\left(d_{2}\right)$ if $-180<I\left(d_{1}\right)-I\left(d_{2}\right) \leq 180$,

$\left\{I\left(d_{1}\right)-I\left(d_{2}\right)+360\right.$ if $I\left(d_{1}\right)-I\left(d_{2}\right)<-180$, $I\left(d_{1}\right)-I\left(d_{2}\right)-360$ if $180 \leq I\left(d_{1}\right)-I\left(d_{2}\right)$,

$I\left(\right.$ opposite $\left.\left(d_{1}\right)\right)=I\left(\operatorname{sub}\left(d_{1}, 180\right)\right)$;
- If $p_{1}$ and $p_{2}$ are locational terms, let $I\left(p_{1}\right)=<x_{p_{1}}, y_{p_{1}}>$ and $I\left(p_{2}\right)=<x_{p_{2}}, y_{p_{2}}>$, then

$$
\begin{aligned}
& I\left(\left|p_{1}, p_{2}\right|\right)=\sqrt{\left(x_{p_{2}}-x_{p_{1}}\right)^{2}+\left(y_{p_{2}}-y_{p_{1}}\right)^{2}}, \\
& I\left(\operatorname{orient}\left(p_{1}, p_{2}\right)\right)=\arctan \left(\left(y_{p_{2}}-y_{p_{1}}\right) /\left(x_{p_{2}}-x_{p_{1}}\right)\right) .
\end{aligned}
$$

The interpretation $I$ and the variable assignment $\beta$ satisfy a wff $\varphi$ (written $I \models \varphi[\beta]$ ) under the conditions:

- $I \models$ term $_{1}=\operatorname{term}_{2}[\beta]$ iff $I\left(\right.$ term $\left.\left._{1}\right)=I(\text { term })_{2}\right)$;

- $I=$ term $_{1}<$ term $_{2}[\beta]$ iff $I\left(\right.$ term $\left.\left._{1}\right)<I(\text { term })_{2}\right)$;

- $I \models \neg \varphi[\beta]$ iff $I \forall \varphi \varphi[\beta]$;

- $I \models\left(\varphi_{1} \wedge \varphi_{2}\right)[\beta]$ iff $I \models \varphi_{1}[\beta]$ and $I \models \varphi_{2}[\beta]$;

- $I \models(\forall v(\varphi))[\beta]$ iff

$$
I \models \varphi\left[\beta_{d / v}\right] \begin{cases}\text { for all } d \in \mathbb{R} & \text { if } v \in T V, \\ \text { for all } d \in \mathbb{R}^{2} & \text { if } v \in L V, \\ \text { for all } d \in \mathbb{R}^{\prime} & \text { if } v \in O V, \\ \text { for all } d \in \mathbb{U} & \text { otherwise. }\end{cases}
$$

\section{Motion in a two-dimensional street network}

We consider the problem of how to get from one place to another in a simple world. The world consists of a two-dimensional street network with traffic lights along streets changing their color periodically, and a robot which moves on the street. We first describe the structure of the street network, how the traffic lights may change, the states of the robot in the space, and the actions this robot can take under different situations. Then we prove that it is possible for a robot to go from one place to another as long as it knows the existing routes and follows the traffic rules.

\subsection{The street network}

A street network consists of streets which intersect, and of places on the street (Figure 1). In the representation of space, places (abstracted as spatial points in the space's coordinate system) are a central notion, and streets (abstracted as straight lines, called paths, which have length $\left|p_{1}, p_{2}\right|$ and direction orient $\left.\left(p_{1}, p_{2}\right)\right)$ are considered to consist of ordered infinite places and are marked by their two end points.

We introduce relations on places and paths: 


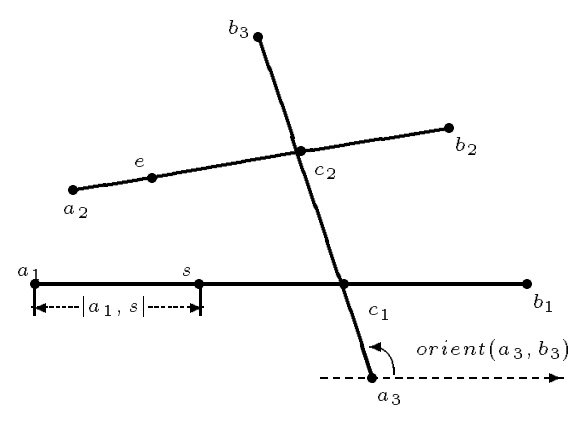

Figure 1: A simple street network

Definition 3.1 Let (a, b) be a path and $\mathrm{p}$ a place other than $\mathrm{a}$ or $\mathrm{b}$. The place $\mathrm{p}$ is on the path $(\mathrm{a}, \mathrm{b})$ if and only if path $(\mathrm{a}, \mathrm{p})$ and path $(\mathrm{p}, \mathrm{b})$ have the same orientation:

on $(p,(a, b))$ iff orient $(a, p)=\operatorname{orient}(p, b)$.

Definition 3.2 Let (a, b) be a path, and $\mathrm{d}$ the value of orient $(\mathrm{a}, \mathrm{b})$. We define a binary relation $\preceq_{d}$ between two places on a path (a, b) with respect to orientation d as:

$p_{1} \preceq_{d} p_{2}$ iff $\left(\left|a, p_{1}\right| \leq\left|a, p_{2}\right|\right) \wedge\left(\left|b, p_{2}\right| \leq\left|b, p_{1}\right|\right)$.

If $p_{1} \preceq_{d} p_{2}$, we say $p_{1}$ precedes $p_{2}$ with respect to the orientation $d$. Therefore, the places on a path are totally ordered with respect to the path's orientation. The relation $\preceq_{d}$ is sometimes written as $\preceq$ if no confusion arises. As usual, $p_{1} \prec p_{2}$ is defined as $p_{1} \preceq p_{2} \wedge p_{1} \neq p_{2}$, and $a \preceq p \preceq b$ is an abbreviation for $a \preceq p \wedge p \preceq b$.

Definition 3.3 Two paths meet if and only if the endpoint of the first path is the starting point of the second path and their orientations are not opposites:

$\operatorname{met}\left(\left(a_{1}, b_{1}\right),\left(a_{2}, b_{2}\right)\right)$ iff

$$
\left(a_{2}=b_{1}\right) \wedge \operatorname{orient}\left(a_{2}, b_{2}\right) \neq \text { opposite }\left(\operatorname{orient}\left(a_{1}, b_{1}\right)\right) \text {. }
$$

Definition 3.4 Two paths cross each other if and only if they have a unique common place:

$$
\begin{aligned}
& \operatorname{cross}\left(\left(a_{1}, b_{1}\right),\left(a_{2}, b_{2}\right)\right) \text { iff } \\
& \quad \exists ! p\left(a_{1} \prec p \prec b_{1} \wedge a_{2} \prec p \prec b_{2}\right) .
\end{aligned}
$$

Given two places in a street network, there may exist some paths connecting them. We call such a sequence of meeting paths a route and assume that circuits are not allowed (i.e., no place appears twice in a route). Thus the linear order relation $\prec$ can be extended to paths with respect to two given places.

Definition 3.5 Let $\left(\mathrm{a}_{1}, \mathrm{~b}_{1}\right)$ and $\left(\mathrm{a}_{2}, \mathrm{~b}_{2}\right)$ be two paths in a street network. Path $\left(\mathrm{a}_{1}, \mathrm{~b}_{1}\right)$ precedes path $\left(\mathrm{a}_{2}, \mathrm{~b}_{2}\right)$ with respect to the route from $\mathrm{a}_{1}$ to $\mathrm{b}_{2}$ (written $\left(\mathrm{a}_{1}, \mathrm{~b}_{1}\right) \preceq\left[\mathrm{a}_{1}, \mathrm{~b}_{2}\right]\left(\mathrm{a}_{2}, \mathrm{~b}_{2}\right)$ ) if and only if path $\left(\mathrm{a}_{1}, \mathrm{~b}_{1}\right)$ meets path $\left(\mathrm{a}_{2}, \mathrm{~b}_{2}\right)$, or there is a path $(\mathrm{a}, \mathrm{b})$ such that path $\left(\mathrm{a}_{1}, \mathrm{~b}_{1}\right)$ meets path $(\mathrm{a}, \mathrm{b})$ and path $(\mathrm{a}, \mathrm{b})$ precedes path $\left(\mathrm{a}_{2}, \mathrm{~b}_{2}\right)$ with respect to the route from a to $\mathrm{b}_{2}$ :

$$
\begin{aligned}
& \left(a_{1}, b_{1}\right) \preceq\left[a_{1}, b_{2}\right]\left(a_{2}, b_{2}\right) \text { iff } \\
& \quad \operatorname{meet}\left(\left(a_{1}, b_{1}\right),\left(a_{2}, b_{2}\right)\right) \vee \\
& \quad \exists a, b\left(\operatorname{met}\left(\left(a_{1}, b_{1}\right),(a, b)\right) \wedge(a, b) \preceq\left[a, b_{2}\right]\left(a_{2}, b_{2}\right)\right) .
\end{aligned}
$$

Definition 3.6 Let $\mathrm{s}$ and e be two places, $\left(\mathrm{a}_{1}, \mathrm{~b}_{1}\right)$ and $\left(\mathrm{a}_{2}, \mathrm{~b}_{2}\right)$ be two paths in a street network. Path $\left(\mathrm{a}_{1}, \mathrm{~b}_{1}\right)$ precedes path $\left(\mathrm{a}_{2}, \mathrm{~b}_{2}\right)$ in the route from $\mathrm{s}$ to $\mathrm{e}$ is defined as:

$$
\begin{aligned}
& \left(a_{1}, b_{1}\right) \preceq_{[s, e]}\left(a_{2}, b_{2}\right) \text { iff } \\
& \quad \exists s^{\prime}, e^{\prime}\left(\left(s, s^{\prime}\right) \preceq_{[s, e]}\left(e^{\prime}, e\right) \wedge\right. \\
& \left.\left(s, s^{\prime}\right) \preceq_{\left[s, b_{1}\right]}\left(a_{1}, b_{1}\right) \preceq_{\left[a_{1}, b_{2}\right]}\left(a_{2}, b_{2}\right) \preceq_{\left[a_{2}, e\right]}\left(e^{\prime}, e\right)\right) .
\end{aligned}
$$

\subsection{Traffic lights}

The street network does not change over time. However, traffic lights located at some places along the street periodically change their color between red and green, where a red light prevents traffic from moving. To represent the traffic lights in the streets, we introduce a function $\operatorname{light}(p, t)$ :

Definition 3.7 The function light $(\mathrm{p}, \mathrm{t})$ has three values $\{0,1,2\}$ where:

$\operatorname{light}(p, t)=$

$\begin{cases}0 & \text { if at time } t \text { there is no traffic light at place } p \\ 1 & \text { if at time } t \text { the traffic light at place } p \text { is red, } \\ 2 & \text { if at time } t \text { the traffic light at place } p \text { is green. }\end{cases}$

The following axioms capture common rules of changing traffic lights:

Axiom 3.1 If there is a traffic light at place $\mathrm{p}$, then it will be either red or green; If there is no traffic light at $\mathrm{p}$, then there is always no traffic light at $\mathrm{p}$ : $\forall p\left(\exists t^{\prime}\left(\operatorname{light}\left(p, t^{\prime}\right) \neq 0\right) \Rightarrow\right.$ $\forall t(\operatorname{light}(p, t)=1 \oplus \operatorname{light}(p, t)=2))$,

$\forall p\left(\exists t^{\prime}\left(\operatorname{light}\left(p, t^{\prime}\right)=0\right) \Rightarrow \forall t(\operatorname{light}(p, t)=0)\right)$. 
Axiom 3.2 A traffic light alternates between red and green on a regular basis (e.g., every

$\mathrm{T}$ time units):

$\forall p, t(\operatorname{light}(p, t)=1 \Rightarrow \operatorname{light}(p, t+T)=2)$,

$\forall p, t(\operatorname{light}(p, t)=2 \Rightarrow \operatorname{light}(p, t+T)=1)$.

From these axioms, we infer the following theorem:

Theorem 3.1 If over $\left(\mathrm{t}_{1}, \mathrm{t}_{2}\right)$ a traffic light is red (green) then over $\left(\mathrm{t}_{1}+\mathrm{T}, \mathrm{t}_{2}+\mathrm{T}\right)$ it is green (red):

$$
\begin{aligned}
& \forall p, t_{1}, t_{2}\left(\forall t^{\prime}\left(t_{1}<t^{\prime} \leq t_{2} \Rightarrow \operatorname{light}\left(p, t^{\prime}\right)=1\right) \Rightarrow\right. \\
& \left.\forall t^{\prime \prime}\left(t_{1}+T<t^{\prime \prime} \leq t_{2}+T \Rightarrow \operatorname{light}\left(p, t^{\prime \prime}\right)=2\right)\right),
\end{aligned}
$$

\subsection{The robot}

We assume there is only one agent, a robot called " $\mathrm{R}$ ", which can move in twodimensional space. To predict that $\mathrm{R}$ will reach its destination if it plans to go from a source place to a goal place, we require its position in the space at different times, the actions it can perform under different situations, and the consequences of different actions.

The robot's state is determined by its location and direction, which are represented by the function $a t(R, p, t)$ and $f a c e(R, d, t)$.

Definition 3.8 The function at $(\mathrm{R}, \mathrm{p}, \mathrm{t}) \mathrm{de-}$ scribes $R$ 's location:

at $(R, p, t)=$

$\{1$ if at time $t R$ is at place $p$,

$\{$ if at time $t R$ is not at place $p$.

Definition 3.9 The function face $(\mathrm{R}, \mathrm{d}, \mathrm{t}) \mathrm{de-}$ scribes $R$ 's direction:

face $(R, d, t)=$

$\{1$ if at time $t R$ faces direction $d$,

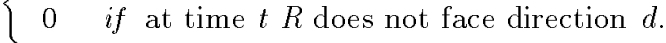

The actions that $\mathrm{R}$ is allowed to perform are move and turn which are described by the functions move_velocity and turn_velocity.

Definition 3.10 The function move_velocity $(R, d, t)$ equals the velocity at which $R$ is moving in direction d at time $\mathrm{t}$.

\footnotetext{
move_velocity $(R, d, t)$

$\int>0$ if at time $t R$ is moving in the direction $d$,

$\{<0$ if at $t R$ is moving in the direction opposite $d$,

Y $=0$ if at time $t R$ is not moving.
}

Definition 3.11 The function

turn_velocity $(R, p, t)$ is the velocity at which $R$ is turning at place $\mathrm{p}$ at time $\mathrm{t}$.

turn_velocity $(R, p, t)$

$\{>0$ if at time $t R$ is turning left at place $p$

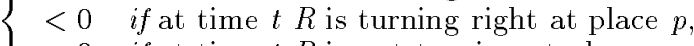

$\{=0$ if at time $t R$ is not turning at place $p$.

The functions move_velocity $(R, d, t)$ and turn_velocity $(R, p, t)$ can be integrated over a time interval $\left(t_{1}, t_{2}\right)$ to represent the length that $\mathrm{R}$ has moved and the angle that $\mathrm{R}$ has turned respectively.

Definition 3.12 Let $(\mathrm{a}, \mathrm{b})$ be a path, $\mathrm{p}_{1}, \mathrm{p}_{2}$ two places on $(\mathrm{a}, \mathrm{b}), \mathrm{d}=\operatorname{orient}(\mathrm{a}, \mathrm{b})$, and $\operatorname{at}\left(\mathrm{R}, \mathrm{p}_{1}, \mathrm{t}_{1}\right)=1, \operatorname{at}\left(\mathrm{R}, \mathrm{p}_{2}, \mathrm{t}_{2}\right)=1$. We define:

$\int_{t_{1}}^{t_{2}}$ move_velocity $(R, d, t) d t=$

$\begin{cases}\left|p_{1}, p_{2}\right| & \text { if } d=\operatorname{orient}\left(p_{1}, p_{2}\right), \\ -\left|p_{1}, p_{2}\right| & \text { if } d=\operatorname{orient}\left(p_{2}, p_{1}\right) .\end{cases}$

\section{Definition 3.13}

Let $\mathrm{p}$ be a place, face $\left(\mathrm{R}, \mathrm{d}_{1}, \mathrm{t}_{1}\right)=1$ and face $\left(\mathrm{R}, \mathrm{d}_{2}, \mathrm{t}_{2}\right)=1$. We define:

$$
\int_{t_{1}}^{t_{2}} \text { turn_velocity }(R, p, t) d t=s u b\left(d_{2}, d_{1}\right) \text {. }
$$

When an agent moves, there is a change in its location but no change in its direction; when it turns, there is a change in its direction but not in its location. This is axiomatized as follows:

Axiom 3.3 If $R$ is at place $\mathrm{p}_{1}$ at time $\mathrm{t}_{1}$, and travels the path $\left(\mathrm{p}_{1}, \mathrm{p}_{2}\right)$ over time interval $\left(\mathrm{t}_{1}, \mathrm{t}_{2}\right)$, then at time $\mathrm{t}_{2} R$ is at place $\mathrm{p}_{2}$ :

$$
\begin{aligned}
& \forall t_{1}, t_{2}\left(\left(a t\left(R, p_{1}, t_{1}\right)=1 \wedge\right.\right. \\
& \left.\int_{t_{1}}^{t_{2}} \text { move_velocity }\left(R, \text { orient }\left(p_{1}, p_{2}\right), t\right) d t=\left|p_{1}, p_{2}\right|\right) \\
& \left.\Rightarrow \operatorname{at}\left(R, p_{2}, t_{2}\right)=1\right) .
\end{aligned}
$$

Axiom 3.4 If $R$ is facing direction $\mathrm{d}_{1}$ at time $\mathrm{t}_{1}$ and turns the angle $\operatorname{sub}\left(\mathrm{d}_{2}, \mathrm{~d}_{1}\right)$ over time interval $\left(\mathrm{t}_{1}, \mathrm{t}_{2}\right)$, then at time $\mathrm{t}_{2} R$ is facing direction $\mathrm{d}_{2}$ :

$$
\begin{aligned}
& \forall t_{1}, t_{2}\left(\left(\operatorname{face}\left(R, d_{1}, t_{1}\right)=1 \wedge\right.\right. \\
& \left.\int_{t_{1}}^{t_{2}} \text { turn_velocity }(R, p, t) d t=\operatorname{sub}\left(d_{2}, d_{1}\right)\right) \\
& \left.\Rightarrow \operatorname{face}\left(R, d_{2}, t_{2}\right)=1\right) .
\end{aligned}
$$

Axiom 3.5 If $R$ is facing direction $\mathrm{d}$ at time $t_{1}$ and moves over time interval $\left(t_{1}, t_{2}\right)$, then at time $\mathrm{t}_{2} R$ is still facing direction $\mathrm{d}$ : 


$$
\begin{aligned}
& \forall d, t_{1}, t_{2}\left(\left(\operatorname{face}\left(R, d, t_{1}\right)=1 \wedge\right.\right. \\
& \left.\forall t\left(t_{1}<t<t_{2} \Rightarrow \text { move_velocity }(R, d, t) \neq 0\right)\right) \\
& \left.\quad \Rightarrow \operatorname{face}\left(R, d, t_{2}\right)=1\right) .
\end{aligned}
$$

Axiom 3.6 If $R$ is at place $\mathrm{p}$ at time $\mathrm{t}_{1}$ and turns over time interval $\left(t_{1}, t_{2}\right)$, then at time $\mathrm{t}_{2} R$ is still at place $\mathrm{p}$ :

$$
\begin{aligned}
& \forall p, t_{1}, t_{2}\left(\left(a t\left(R, p, t_{1}\right)=1 \wedge\right.\right. \\
& \left.\forall t\left(t_{1}<t<t_{2} \Rightarrow \text { turn_velocity }(R, p, t) \neq 0\right)\right) \\
& \left.\Rightarrow a t\left(R, p, t_{2}\right)=1\right) .
\end{aligned}
$$

\subsection{Moving from one place to another}

The particular problem we are interested in is that of a robot moving from place $s$ to place $e$ on a given route. The robot may encounter traffic lights along the way and must stop for red ones. We want to prove that the robot will eventually reach its destination. If a departure time and velocities are given, then we also want to approximate the arrival time. To solve this problem, we need axioms to capture how the robot applies its knowledge to guide its motion along streets.

Axiom 3.7 If $R$ is moving on path ( $\mathrm{a}, \mathrm{b})$ towards $\mathrm{b}$ then $R$ keeps moving until it encounters a red light or a corner for turning, or reaches b:

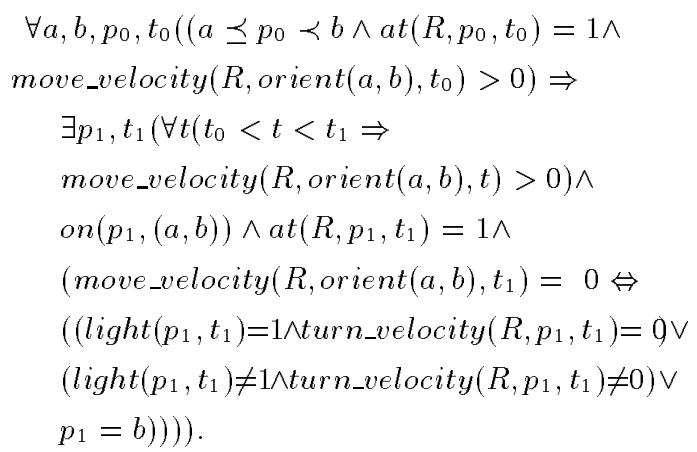

Axiom 3.8 If $R$ is waiting for a red light at place $\mathrm{p}_{0}$ and facing direction $\mathrm{d}$, when the light turns green, $R$ moves forward or turns:

$$
\begin{aligned}
& \forall d, p_{0}, t_{0}\left(\left(\operatorname{light}\left(p_{0}, t_{0}\right)=1 \wedge\right.\right. \\
& \operatorname{at}\left(R, p_{0}, t_{0}\right)=1 \wedge \operatorname{face}\left(R, d, t_{0}\right)=1 \wedge \\
& \text { move_velocity }\left(R, d, t_{0}\right)=0 \wedge \\
& \text { turn_velocity } \left.\left(R, p_{0}, t_{0}\right)=0\right) \Rightarrow \\
& \quad \exists t_{1}\left(\forall t \left(t_{0}<t<t_{1} \Rightarrow(\text { move_velocity }(R, d, t)=0 \wedge\right.\right. \\
& \left.\left.\quad \text { turn_velocity }\left(R, p_{0}, t\right)=0\right)\right) \wedge
\end{aligned}
$$

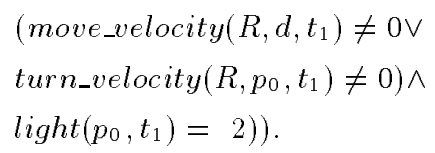

Axiom 3.9 If $R$ is moving on path $\left(\mathrm{a}_{1}, \mathrm{~b}_{1}\right)$ towards a destination, and path $\left(\mathrm{a}_{1}, \mathrm{~b}_{1}\right)$ meets and precedes path $\left(\mathrm{a}_{2}, \mathrm{~b}_{2}\right)$, then $R$ will turn when it reaches place $\mathrm{b}_{1}$ and continue moving on path $\left(\mathrm{a}_{2}, \mathrm{~b}_{2}\right)$ :

$$
\begin{aligned}
& \forall a_{1}, a_{2}, b_{1}, b_{2}\left(\left(\exists p_{0}, t_{0}, t_{b}\left(p_{0} \prec b_{1} \wedge t_{0}<t_{b} \wedge\right.\right.\right. \\
& \text { at }\left(R, p_{0}, t_{0}\right)=1 \wedge \\
& \left.\int_{t_{0}}^{t_{b}} \text { move_velocity }\left(R, \text { orient }\left(a_{1}, b_{1}\right), t\right) d t=\left|p_{0}, b_{1}\right|\right) \wedge \\
& \text { meet } \left.\left(\left(a_{1}, b_{1}\right),\left(a_{2}, b_{2}\right)\right) \wedge\left(a_{1}, b_{1}\right) \preceq\left(a_{2}, b_{2}\right)\right) \Rightarrow \\
& \quad \exists t_{b}^{\prime \prime}\left(\int_{t_{b}}^{t_{b}^{\prime \prime}} \text { turn_velocity }\left(R, b_{1}, t\right) d t=\right. \\
& \quad \operatorname{sub}\left(\text { orient }\left(a_{2}, b_{2}\right), \text { orient }\left(a_{1}, b_{1}\right)\right) \wedge \\
& \quad \forall d, t\left(t_{b} \leq t<t_{b}^{\prime \prime} \Rightarrow\right. \\
& \left.\quad\left(\text { at }\left(R, b_{1}, t\right)=1 \wedge \text { move_velocity }(R, d, t)=0\right)\right) \wedge \\
& \quad \text { face }\left(R, \text { orient }\left(a_{2}, b_{2}\right), t_{b}^{\prime \prime}\right)=1 \wedge \\
& \left.\left.\quad \text { move_velocity }\left(R, \text { orient }\left(a_{2}, b_{2}\right), t_{b}^{\prime \prime}\right)>0\right)\right) .
\end{aligned}
$$

To predict an approximate time $t$ at which $\mathrm{R}$ reaches its destination, we introduce function $\min \left(x_{1}, x_{2}, f\left(r_{1}, \ldots, r_{i}, x, r_{i+1}, \ldots, r_{n}\right)\right)$ which has the minimum value of the function $f\left(r_{1}, \ldots, r_{i}, x, r_{i+1}, \ldots, r_{n}\right)$ when its parameter $x$ varies over the range $\left[x_{1}, x_{2}\right]$.

Theorem 3.2 If $R$ is moving on a path $(\mathrm{a}, \mathrm{b})$ towards b without going backwards or stopping, then the time $t_{b}$ when it reaches $b$ is bounded as follows:

$$
\begin{aligned}
& \forall a, b, p_{0}, t_{0}, t_{b}\left(\left(a \preceq p_{0} \prec b \wedge a t\left(R, p_{0}, t_{0}\right)=1 \wedge\right.\right. \\
& \text { move_velocity }\left(R, \text { orient }(a, b), t_{0}\right)>0 \wedge \\
& \forall t\left(t_{0}<t<t_{b} \Rightarrow \text { move_velocity }(R, \operatorname{orient}(a, b), t)>0\right) \wedge \\
& \text { at } \left.\left(R, b, t_{b}\right)=1\right) \Rightarrow \\
& \quad t_{b}-t_{0} \leq\left|p_{0}, b\right| / \\
& \left.\quad \min \left(t_{0}, t_{b}, \text { move_velocity }(R, \operatorname{orient}(a, b), t)\right)\right) .
\end{aligned}
$$

Theorem 3.3 If at time $\mathrm{t}_{\mathrm{b}} R$ begins turning from a path $(\mathrm{a}, \mathrm{b})$ to a path $(\mathrm{b}, \mathrm{c})$, then the time $t_{b}^{\prime}$ when it is on path $(\mathrm{b}, \mathrm{c})$ is bounded as follows:

$$
\begin{gathered}
\forall a, b, c, t_{b}, t_{b}^{\prime}\left(\left(\operatorname{face}\left(R, \text { orient }(a, b), t_{b}\right)=1 \wedge\right.\right. \\
\text { turn_velocity }\left(R, b, t_{b}\right) \neq 0 \wedge \\
\forall t\left(t_{b}<t<t_{b}^{\prime} \Rightarrow \text { turn_velocity }(R, b, t) \neq 0\right) \wedge \\
\text { face } \left.\left(R, \text { orient }(b, c), t_{b}^{\prime}\right)=1\right) \Rightarrow \\
t_{b}^{\prime}-t_{b} \leq \operatorname{sub}(\text { orient }(b, c), \text { orient }(a, b)) \\
\left./ \min \left(t_{b}, t_{b}^{\prime}, \text { turn_velocity }(R, b, t)\right)\right) .
\end{gathered}
$$




\subsection{Example}

We conclude with an example where we prove that it is possible for the robot to get from one place to another.

A robot $R$ is moving from place $s$ to place $e$ and there is a traffic light at both places $c_{1}$ and $c_{2}$ (Figure 1) which change color (red,green) every $\mathrm{T}$ time units:

Given

1. Structure of streets:

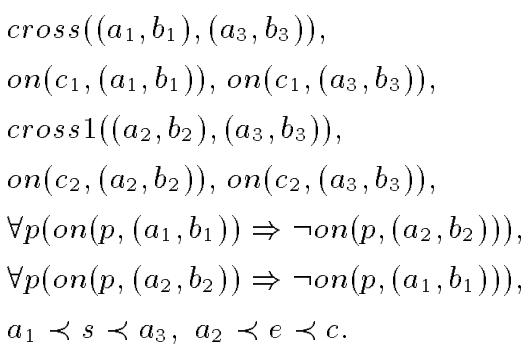

2. Traffic lights:

$$
\begin{aligned}
& \forall t\left(\operatorname{light}\left(c_{1}, t\right) \neq 0\right), \forall t\left(\operatorname{light}\left(c_{2}, t\right) \neq 0\right), \\
& \forall p, t\left(p \neq c_{1} \wedge p \neq c_{2} \wedge\right. \\
& \left(\operatorname{on}\left(p,\left(a_{1}, b_{1}\right)\right) \vee \operatorname{on}\left(p,\left(a_{2}, b_{2}\right)\right) \vee \operatorname{on}\left(p,\left(a_{3}, b_{3}\right)\right) \Rightarrow\right. \\
& \quad \operatorname{light}(p, t)=0) .
\end{aligned}
$$

3. Robot's initial state:

$\operatorname{at}\left(R, s, t_{s}\right)=1$,

face $\left(R, \operatorname{orient}\left(s, a_{3}\right), t_{s}\right)=1$,

move_velocity $\left(R, \operatorname{orient}\left(a_{1}, a_{3}\right), t_{s}\right)>0$.

We can derive

1. There is no triffic light between $s$ and $c_{1}$ : $\forall p, t\left(s \prec p \prec c_{1} \Rightarrow\right.$ turn_velocity $\left.(R, p, t)=0\right)$.

2. There is a time $t_{c_{1}}$ when $\mathrm{R}$ is at $c_{1}$ :

$$
\begin{aligned}
& \exists t_{c_{1}}\left(\forall t \left(t_{s}<t<t_{c_{1}} \Rightarrow\right.\right. \\
& \text { move_velocity } \left.\left(R, \text { orient }\left(a_{1}, b_{1}\right), t\right)>0\right) \wedge \\
& \text { at }\left(R, c_{1}, t_{c_{1}}\right)=1 \wedge \\
& \left(\text { move_velocity }\left(R, \text { orient }\left(a_{1}, b_{1}\right), t_{c_{1}}\right)=0 \Leftrightarrow\right. \\
& \left(\left(\text { light }\left(c_{1}, t_{c_{1}}\right)=1 \wedge \text { turn_velocity }\left(R, c_{1}, t_{c_{1}}\right)=0\right) \vee\right. \\
& \left.\left.\left.\left(\text { light }\left(c_{1}, t_{c_{1}}\right) \neq 1 \wedge \text { turn_velocity }\left(R, c_{1}, t_{c_{1}}\right) \neq 0\right)\right)\right)\right) .
\end{aligned}
$$

- given 2, 3, derived 1 and Axiom 3.7

3. Time $t_{c_{1}}$ is bounded as follows:

$$
t_{c_{1}}-t_{s} \leq\left|s, c_{1}\right|
$$

$/ \min \left(t_{s}, t_{c_{1}}\right.$, move_velocity $\left.\left(R, \operatorname{orient}\left(a_{1}, b_{1}\right), t\right)\right)$.

$$
\text { - given 3, derived } 2 \text { and Theorem } 3.2
$$

4. At time $t_{c_{1}}, \mathrm{R}$ is still facing $b_{1}$ :

$\operatorname{face}\left(R, \operatorname{orient}\left(a_{1}, b_{1}\right), t_{c_{1}}\right)=1$.

- given 3, derived 2 and Axiom 3.5

5. Over the time interval $\left(t_{s}, t_{c_{1}}\right)$, R travels subpath $\left(s, c_{1}\right)$ :

$\int_{t_{s}}^{t_{c_{1}}}$ move_velocity $\left(R, \operatorname{orient}\left(a_{1}, b_{1}\right), t\right) d t=\left|s, c_{1}\right|$.

- given 3, derived 2 and Definition 3.12

6. Path $\left(s, c_{1}\right)$ meets and precedes path $\left(c_{1}, c_{2}\right)$ :

$\operatorname{meet}\left(\left(s, c_{1}\right),\left(c_{1}, c_{2}\right)\right) \wedge\left(s, c_{1}\right) \preceq_{[s, e]}\left(c_{1}, c_{2}\right)$.

- given 1 and Definition 3.6

7. There is a time $t_{c_{1}}^{\prime \prime}$ such that over time interval $\left(t_{c_{1}}, t_{c_{1}}^{\prime \prime}\right) \mathrm{R}$ turns from facing $\operatorname{orient}\left(a_{1}, b_{1}\right)$ to facing orient $\left(a_{3}, b_{3}\right)$ :

$\exists t_{c_{1}}^{\prime \prime}\left(\int_{t_{c_{1}}}^{t_{c_{1}}^{\prime \prime}}\right.$ turn_velocity $\left(R, c_{1}, t\right) d t=$

$\operatorname{sub}\left(\operatorname{orient}\left(a_{3}, b_{3}\right), \operatorname{orient}\left(a_{1}, b_{1}\right)\right) \wedge$

$\forall d, t\left(t_{c_{1}} \leq t<t_{c_{1}}^{\prime \prime} \Rightarrow\left(\operatorname{at}\left(R, c_{1}, t\right)=1 \wedge\right.\right.$

move_velocity $(R, d, t)=0)) \wedge$

$\operatorname{face}\left(R, \operatorname{orient}\left(a_{3}, b_{3}\right), t_{c_{1}}^{\prime \prime}\right)=1 \wedge$

move_velocity $\left.\left(R, \operatorname{orient}\left(a_{3}, b_{3}\right), t_{c_{1}}^{\prime \prime}\right)>0\right)$.

- given 3, derived 5, 6 and Axiom 3.9

8. If at time $t_{c_{1}}$ the traffic light at place $c_{1}$ is green:

(a) $\operatorname{light}\left(c_{1}, t_{c_{1}}\right)=2$.

- assumption

(b) At time $t_{c_{1}}, \mathrm{R}$ is turning at place $c_{1}$ : $\operatorname{at}\left(R, c_{1}, t_{c_{1}}\right)=1 \wedge$ turn_velocity $\left(R, c_{1}, t_{c_{1}}\right) \neq 0$.

- derived 8(a), 7 and 2

(c) Time $t_{c_{1}}^{\prime \prime}$ is bounded as follows:

$$
\begin{gathered}
t_{c_{1}}^{\prime \prime}-t_{c_{1}} \leq \operatorname{sub}\left(\operatorname{orient}\left(a_{3}, b_{3}\right), \operatorname{orient}\left(a_{1}, b_{1}\right)\right) \\
/ \min \left(t_{c_{1}}, t_{c_{1}}^{\prime \prime}, \text { turn_velocity }\left(R, c_{1}, t\right)\right) \\
\text { - derived } 4,8(\mathrm{~b}), 7 \text { and Theorem } 3.3
\end{gathered}
$$

9. If at time $t_{c_{1}}$ the traffic light at place $c_{1}$ is red:

(a) $\operatorname{light}\left(c_{1}, t_{c_{1}}\right)=1$.

$$
\text { - assumption }
$$

(b) At time $t_{c_{1}}, \mathrm{R}$ is waiting at place $c_{1}$ : $\operatorname{at}\left(R, c_{1}, t_{c_{1}}\right)=1 \wedge$ turn_velocity $\left(R, c_{1}, t_{c_{1}}\right)=0 \wedge$ move_velocity $\left(R\right.$, orient $\left.\left(a_{1}, b_{1}\right), t_{c_{1}}\right)=0$. 
- derived $9(\mathrm{a}), 7$ and 2

(c) There is a time $t_{c_{1}}^{\prime}$ when the traffic light at place $c_{1}$ is green:

$$
\begin{aligned}
\exists t_{c_{1}}^{\prime}\left(t_{c_{1}} \leq t_{c_{1}}^{\prime}\right. & \left.<t_{c_{1}}+T \wedge \operatorname{light}\left(c_{1}, t_{c_{1}}^{\prime}\right)=2\right) . \\
& - \text { derived } 9(\mathrm{a}) \text { and Theorem } 3.1
\end{aligned}
$$

(d) Over the time interval $\left(t_{c_{1}}, t_{c_{1}}^{\prime}\right), \mathrm{R}$ is waiting:

$$
\begin{aligned}
& \forall t\left(t_{c_{1}}<t<t_{c_{1}}^{\prime} \Rightarrow\right. \\
& \left(\text { move_velocity }\left(R, \text { orient }\left(a_{1}, b_{1}\right), t\right)=0 \wedge\right. \\
& \text { turn_velocity } \left.\left(R, c_{1}, t_{c_{1}}\right)=0\right) \wedge \\
& \left(\text { move_velocity } \left(R, \text { orient }_{\left.\left(a_{1}, b_{1}\right), t_{c_{1}}^{\prime}\right) \neq 0 \vee}\right.\right. \\
& \text { turn_velocity } \left.\left(R, c_{1}, t_{c_{1}}^{\prime}\right) \neq 0\right) . \\
& \quad-\text { derived } 9(\mathrm{a}), 9(\mathrm{~b}), 4,9(\mathrm{c}) \text { and Axiom } 3.8
\end{aligned}
$$

(e) At time $t_{c_{1}}^{\prime}, \mathrm{R}$ is still facing $b_{1}$ :

$\operatorname{face}\left(R, \operatorname{orient}\left(a_{1}, b_{1}\right), t_{c_{1}}^{\prime}\right)=1$.

- derived 4,9(d) and Axiom 3.4

(f) At time $t_{c_{1}}^{\prime}, \mathrm{R}$ is turning at place $c_{1}$ : $\operatorname{at}\left(R, c_{1}, t_{c_{1}}^{\prime}\right)=1 \wedge$ turn_velocity $\left(R, c_{1}, t_{c_{1}}^{\prime}\right) \neq 0$.

- derived 7 and $9(\mathrm{~d})$

(g) Time $t_{c_{1}}^{\prime \prime}$ is bounded as follows:

$$
\begin{gathered}
t_{c_{1}}^{\prime \prime}-t_{c_{1}}^{\prime} \leq s u b\left(\operatorname{orient}\left(a_{3}, b_{3}\right), \operatorname{orient}\left(a_{1}, b_{1}\right)\right) \\
/ \min \left(t_{c_{1}}^{\prime}, t_{c_{1}}^{\prime \prime}, \text { turn_velocity }\left(R, c_{1}, t\right)\right) .
\end{gathered}
$$

- derived $9(\mathrm{e}), 9(\mathrm{f}), 9(\mathrm{~g}), 7$ and Theorem 3.3

10. At time $t_{c_{1}}^{\prime \prime}, \mathrm{R}$ is still at $c_{1}$ :

$\operatorname{at}\left(R, c_{1}, t_{c_{1}}^{\prime \prime}\right)=1$.

- derived 7, 2 and Axiom 3.3

11. There is a bounded time $t_{c_{2}}^{\prime \prime}$ such that $\mathrm{R}$ is moving at place $c_{2}$ towards $e$ :

$\exists t_{c_{2}}^{\prime \prime}\left(\operatorname{at}\left(R, c_{2}, t_{c_{2}}^{\prime \prime}\right)=1 \wedge\right.$

$\operatorname{face}\left(R, \operatorname{orient}\left(a_{2}, b_{2}\right), t_{c_{2}}^{\prime \prime}\right)=1 \wedge$

move_velocity $\left.\left(R, \operatorname{orient}\left(a_{2}, b_{2}\right), t_{c_{2}}^{\prime \prime}\right)>0\right)$.

- derived 10, 7 , given 1, 2 ,

and apply derived 1 - 9 again

12. There is a bounded time $t_{e}$ when $\mathrm{R}$ reaches $e$ :

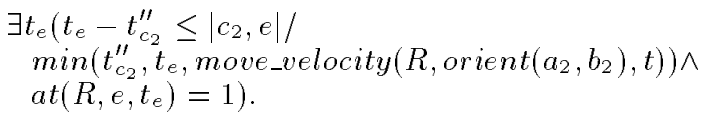

- derived 11, given 1, 2 and Axiom 3.7, Theorem 3.2

\section{Conclusions}

Space and time must be taken into account when commonsense knowledge such as how to get from one place to another is represented in a computer. However, previous work $[4,3,1]$ in this area either ignores the temporal feature of motion in space or does not give a proper description of spatial structure for reasoning about motion in space. In this paper we presented a spatio-temporal logic and showed how to represent the common knowledge of a two-dimensional street network with active traffic lights, and how to formalize the commonsense reasoning problem of going from one place to another in this street network. The proposed logic is also suitable for representing and reasoning about motion in three-dimensional world.

\section{Acknowledgements}

The first author is supported by an Acadia Graduate Fellowship. The second author is supported by NSERC grant OGP0046773.

\section{References}

[1] E. Davis. Representation of commonsense knowledge. Morgan Kaufmann, 1990.

[2] S. Goodwin, E. Neufeld, and A. Trudel. Temporal reasoning with real valued functions. In Proc. of the 2nd Pacific Rim International Conference on Artificial Intelligence, Seoul, Korea, 1992.

[3] J. A. G. M. Koomen. Reasoning about recurrence. Int. J. of Intelligence Systems, 6:461-496, 1991.

[4] B. Kuipers. Modeling spatial knowledge. In Su-Shing Chen, editor, Advances in Spatial Reasoning, volume 2, pages 171198. Ablex Publishing Co., 1990. 